\title{
Individual Software Plan for the Programmable Logic Controller
}

\author{
Richard Green
}

July 28, 1997

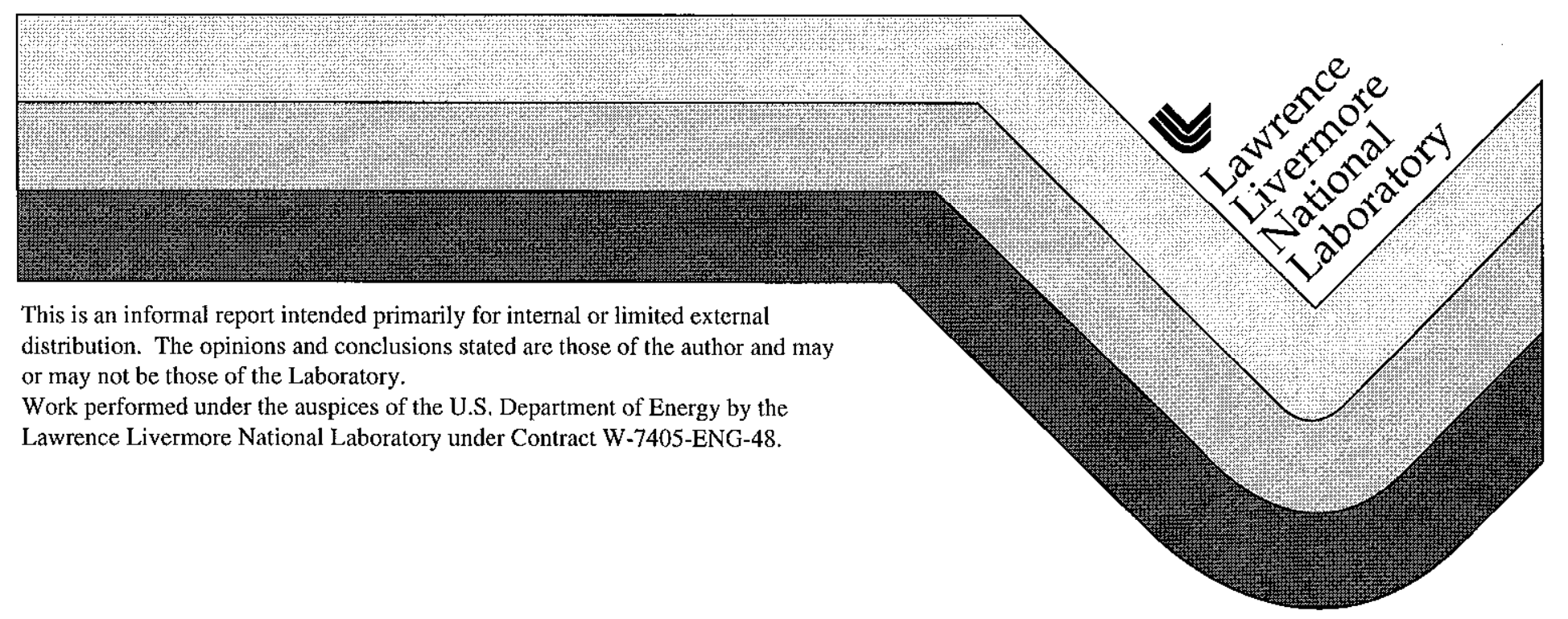


This document was prepared as an account of work sponsored by an agency of the United States Government. Neither the United States Government nor the University of California nor any of their employees, makes any warranty, express or implied, or assumes any legal liability or responsibility for the accuracy, completeness, or usefulness of any information, apparatus, product, or process disclosed, or represents that its use would not infringe privately owned rights. Reference herein to any specific commercial product, process, or service by trade name, trademark, manufacturer, or otherwise, does not necessarily constitute or imply its endorsement, recommendation, or favoring by the United States Government or the University of California. The views and opinions of authors expressed herein do not necessarily state or reflect those of the United States Government or the University of California, and shall not be used for advertising or product endorsement purposes.

This report has been reproduced directly from the best available copy.

Available to DOE and DOE contractors from the

Office of Scientific and Technical Information

P.O. Box 62, Oak Ridge, TN 37831

Prices available from (423) 576-8401

Available to the public from the

National Technical Information Service

U.S. Department of Commerce

5285 Port Royal Rd.,

Springfield, VA 22161 
Individual Software Plan for the Programmable Logic Controller

\section{REVISION HISTORY}

Rev. No. CNNo. Effective Date 'Description of Revision/CN

0

$0 \quad$ CN ISP-CM-01-0-1 04/10/97

$0 \quad$ CNISP-CM-01-0-2 07/28/97
09/17/96
Original issue.

Text changes for clarification; addition of Appendix A. Affects Titte Page, pages 3,5 , and 8 of 11 , and Appendix A.

Addition of Section 7.0. Affects Title Page and page 9 of 11 .

APPROVALS:

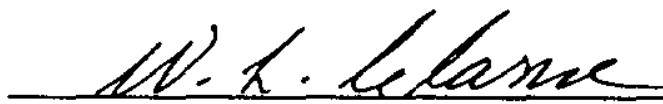

W.L. Clarke, CRWMS LLNL Manager<smiles>CCC12CCCC(CC1)C2=O</smiles>

R.E. Monks, MofO LLNL Engineering Asst ance Manager

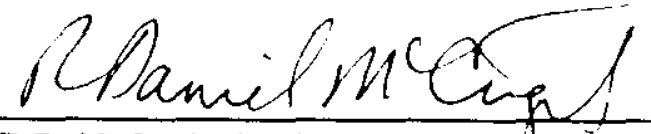

R.D. McCright, Technical Area Ledder
Richard Green 
Effective Date: 09/17/96

ISP-CM-01

Revision 0

\section{LLNL-YMP}

Individual Software Plan for the Programmable Logic Controller

Reviewed by:
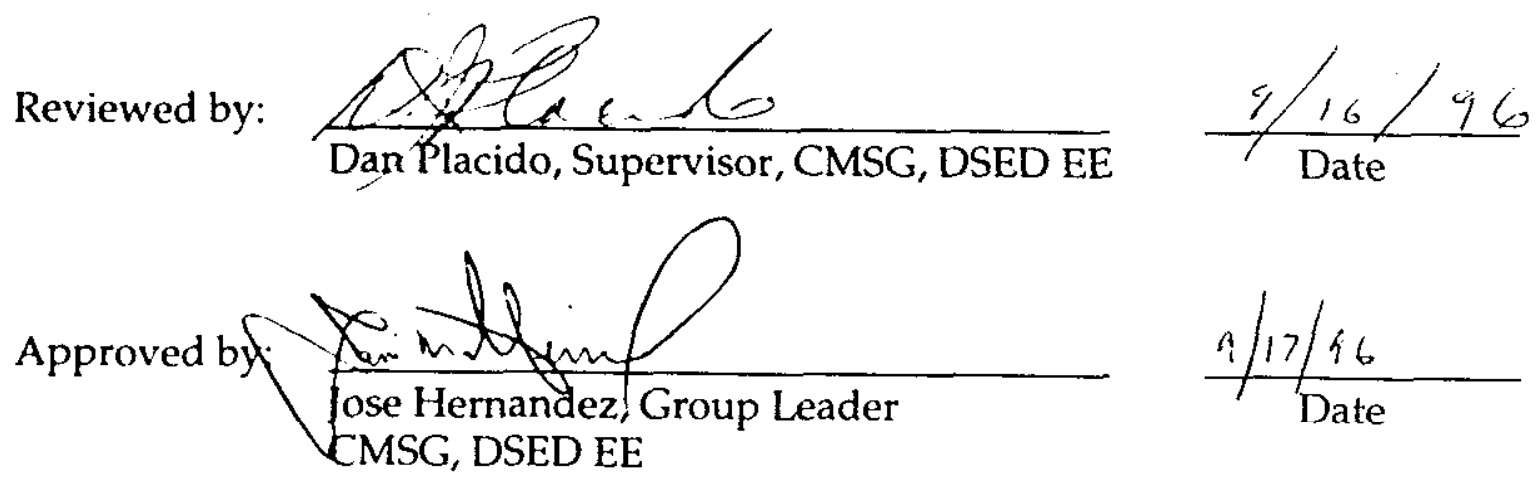
1.0 PURPOSE

This document defines the software quality assurance plan (SQAP) as it shall be applied to the development of the monitor and control system for the Integrated Corrosion Facility (ICF). The purpose of this SQA plan is to provide guidance to the development team in software quality and associated documentation.

The following documents form the basis of this SQAP:

1) ANSI/lEEE Std 7.30-1989, IEEE Standard for Software Quality Assurance Plans

2) C\&MS 92-902 Chemistry \& Material Science Software Quality Assurance Plan

\subsection{Scope}

The scope of this document covers all software produced during the Integrated Corrosion Facility development.

For the purpose of this SQAP. the term quality assurance means a planned and systematic pattern of all actions necessary to provide adequate confidence that the product conforms to established technical requirements.

For the purpose of this SQAP, the term software includes the documentation and data, and execution control statements (e.g., command files, Job Control Language, etc.).

The software products covered by this SQAP are:

1) PLC ladder logic software.

2) Man-Machine Interface (MMI) configuration software.

3) CMS 96-054, System Test Plan and System Operation and Verification Test Procedure.

\subsection{Acronyms}

FDR Final Design Review

GUI Graphical User Interface

MMI Man-Machine Interface

PLC Programmable Logic Controller

SCMP Software Configuration Management Plan

SQAP Software Quality Assurance Plan

SQMP Software Quality Management Plan 


\begin{tabular}{|l|l|l|l|l|}
\hline No.: & Revision: & Pate: & Page: \\
ISP-CM-01 & 0 & $09 / 17 / 96$ & 4 & 11 \\
\hline
\end{tabular}

SRR System Requirements Review

STP System Test Plan

TSR Test Summary Report

\subsection{References}

1) ICF Specification/Requirements for Process Monitor and Control

2) ANSI/IEEE Std 730-1989, IEEE Standard for Software Quality Assurance Plans

3) C\&MS 92-902 Chemistry \& Material Science Software Quality Assurance Plan

\subsection{MANAGEMENT}

\subsection{Software Life Cycle Tasks}

The software life cycle tasks covered by this SQA Plan include the Following:

- Analysis and documentation of requirements

- Design and documentation of software subsystems

- Testing and documentation of functional and performance tests

- Software configuration management (change/version control)

\subsection{Responsibility}

Specific organizational elements responsible for the tasks in support of the Integrated Corrosion Facility process monitor control SQA are as follows:
Lead Experimenter:
Dan McCright
ICF Project Engineer:
Gregory Gdowski
Project Mechanical:
Stanley Edson
Project Electronics:
Richard Green

\subsection{Computer Application Classification Level}

The PLC and computer monitor and control system merits a Level 2 classification as defined by the Chemistry \& Material Science Software Quality Assurance Plan (C\&MS 92-902), section 7.2 because it: 1) requires high reliability and 2 ) requires formal documentation to support validity. 


\subsection{Purpose}

The ICF project software documentation is designed to govern the development, verification, use, and maintenance of the software.

\subsection{Required Documents}

\subsubsection{System Requirements and Functional Specification (SRFS)}

A SRFS to establish the objectives and requirements of the monitor and control system shall be documented prior to final software design. The Integrated Corrosion Facility Specifications/ Requirements for Process Monitor and Control shall serve as this document.

The SRFS will be reviewed by the Lead Experimenter, Project Engineer, Project Mechanical Engineer, and Project Electronics Engineer.

\subsubsection{System Test Plan (STP)}

Before testing occurs, a STP will identify and describe test items, test equipment, the features to be tested, the testing tasks, who will perform each task, and any risks involved. The STP is included as Appendix A.

\subsubsection{Test Summary Report (TSR)}

The TSR will contain the results of the testing activities. It will include at test log, test incident reports, and test summary report.

\subsubsection{Software Configuration Management Plan (SCMP)}

The SCMP is included in section 6.0 of this document.

\subsubsection{System User Manual}

User documentation will be provided. This shall be sufficient to allow the user to understand the purpose and the operation of the system, how it works and how to use and maintain it.

\subsection{REVIEWS AND AUDITS}

\subsection{Purpose}

This section defines the formal technical and managerial reviews and audits that will be conducted. These reviews and audits will not take the place of informal walk-through that will occur throughout the software development process. 


\subsection{Minimum Requirements}

As a minimum, the following reviews and audits shall be conducted.

\subsubsection{Software Requirements Review (SRR)}

The SRR will be held to ensure the adequacy of requirements stated in the SRFS.

\subsubsection{Final design review (FDR)}

The FDR or detailed design review will be held to determine the acceptability of the detailed system design in satisfying the requirements of the SRFS.

\subsubsection{Code walk-through}

A code walk-through will be held to examine the acceptability of the PLC code written to satisfy the requirements of the SRFS.

\subsubsection{Software Test Review (STR)}

The STR will evaluate the adequacy and completeness of the test methods defined in the STP. The STR will determine the readiness of the software testing to move from the unit tests to the system tests.

\subsubsection{Physical Audit}

Physical audits will be held to assure that the documentation to be delivered correctly describes the code. The physical audit should include:

1) All software products

2) Associated documentation

\subsection{TESTING PLAN}

\subsection{Developer Test Phase}

Unit or module testing will be conducted by the software developers prior to integrated testing.

\subsection{Integration Test Phase (Acceptance Testing)}

Integration testing will be conducted according to the Software Test Plan. Following integration testing, a Software Test Report will be written which will include the results of the tests. 


\subsection{Purpose}

The configuration management describes the methods for identifying software product items, controlling and implementing changes, and recording and reporting change implementation status.

\subsection{Scope}

The configuration management for the Integrated Corrosion Facility PLC System covers all software required for operation. This includes vendor supplied (commercial) programs and programs generated at LLNL. Any changes to system hardware is beyond the scope of this ISP.

\subsection{Naming Convention}

\subsubsection{PLC Software}

The ICF PLC software shall be written in the language used by the PLC selected for this task. The program name shall reflect the project identification code ICFxx. The xx refers to the version of the software.

\subsubsection{Software}

The ICF MMI configuration software shall be written in a language compatible with the PLC selected for this task. The program name shall reflect the project identification code ICFxx. The xx refers to the version of the software.

\subsection{Software Backups}

A backup of the program shall be copied to floppy disk or other suitable magnetic storage media, whenever any changes are made to the software. A copy of the most recent version shall be stored in the project QA file.

A complete diagram of the program shall be made when a version change is made. This shall be placed in a notebook or file in the ICF laboratory.

\subsection{Ladder-logic diagrams}

A copy of the ladder-logic diagrams depicting the process control and monitoring programming of the PLC shall be kept in a file or notebook in the ICF laboratory. A copy shall also be part of the documentation of section (User Documentation). 
6.6 Man-Machine Interface configuration database

A copy of the MMI configuration database shall be kept in a file or notebook in the ICF laboratory. A copy shall also be part of the documentation of section (User Documentation).

\subsection{Vaulted Drawings}

A full set of drawings of the ICF system. chassis wiring diagrams, system wiring diagrams, ladder-logic and MMI database shall be kept in a file or notebook in the ICF laboratory. A second copy will be vaulted as a permanent record.

\subsection{Software Change Procedure}

\subsubsection{Software Change Request Procedure}

All software problems or changes in requirements identified during the development process shall be reported to the project EE who will be responsible for their final resolution.

Any changes after installation and final review will require the following administrative procedure:

1) A change request form is submitted to the project EE using the Integrated Corrosion Facility Software Change Request Form (included as Exhibit $\mathbf{A}$ ). The change request form will be used to facilitate one change only. If two "distinct" changes are required, two change request forms must be submitted. The project EE is responsible for tracking and ensuring the change are completed in a timely manner. The Project EE will confer with the Project Engineer to ensure that all other components of the system are taken into consideration when deciding if the request will be granted.

2) The Project EE and Project Engineer will sign and date the change request form, and designate their approval/rejection of the request. In either case, the change request originator will be notified of the status of the request.

The person assigned to implement a software change will receive an approved Integrated Corrosion Facility Change Request Form identifying the change the required change. Software changes are then implemented as follows:

1) Obtain a copy of the pertinent document and software from the Integrated Corrosion Facility QA file. This shall include a blank copy of the Integrated Corrosion Facility Software Modification Report Form (included as Exhibit B).

2) Mark-up necessary documents to indicate the changes to be made. Complete the Integrated Corrosion Facility Software Modification Report. 


\begin{tabular}{|c|c|c|c|c|c|}
\hline No: & Revision: & Date: & Page: & & \\
\hline ISP-CM-01 & CN ISP-CM-01-0-2 & $07 / 28 / 97$ & 9 & of & 11 \\
\hline
\end{tabular}

3) Implement the changes to the software.

4) Unit test the changes while documenting the tests and results.

5) Certify the changes via successful execution of tests in accordance with the software test plan.

6) Conduct a code walk-through with peer group members.

7) Review certified changes with Project EE and Project Engineer.

8) Return the updated software and the completed ICFSMR form to the Integrated Corrosion Facility QA file for storage.

\subsection{Code and media storage}

For the purpose of clarity, the term record as used in this section will refer to software documentation, required SQA documents as identified in section 3 of this document.

All records will be stored in the ICF QA file. As updates to the records are made, a new copy of the record will replace the older version. These records will be retained in the QA file for as long as the ICF MMI and PLC system is existence.

\subsubsection{Code control}

Four validated copies of the current software will be maintained for the ICF project. Copies of the software will be stored as follows:

1) Two copies will be stored in the ICF QA file.

2) One copy will be stored with the Chemistry \& Material Science computer system archives.

3) One copy will be stored with the YMP system archives.

\subsection{Records}

\subsubsection{Quality Assurance Records}

Non-permanent QA Records:

None

\section{Retained as Iifetime QA Records:}

Lifetime QA Records generated are as indicated in section 3.2.2.12 of procedure 033-YMP-QP 3.2, "Software Quality Assurance." 


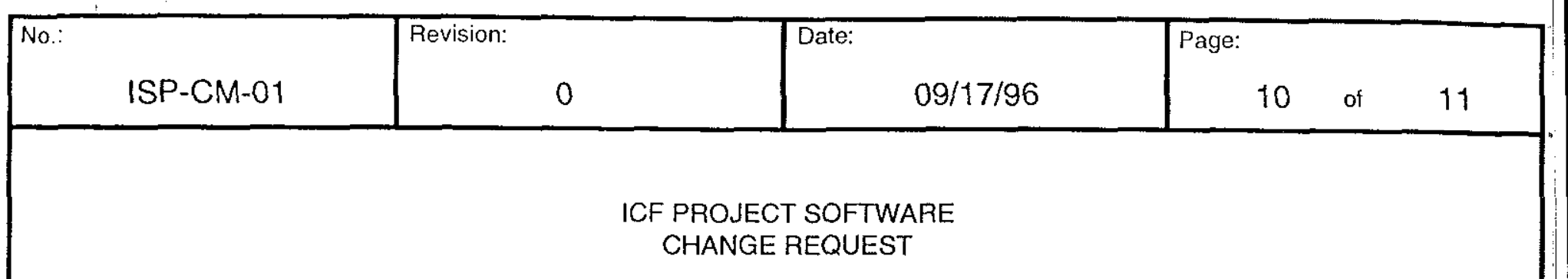

Change request item:

Date Submitted:

Requester's Name:

Requesters Title:

(1)

System changed:

PLC

MMI

Change request type:

Priority level:

Systems Impacted:

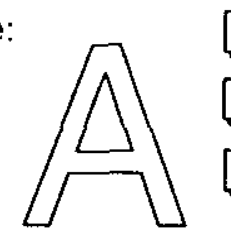

Bug Report

Routine

Operational Change

New Function

Mechanical

$\square$ Urgent

D Electrical

Software

Description of change:

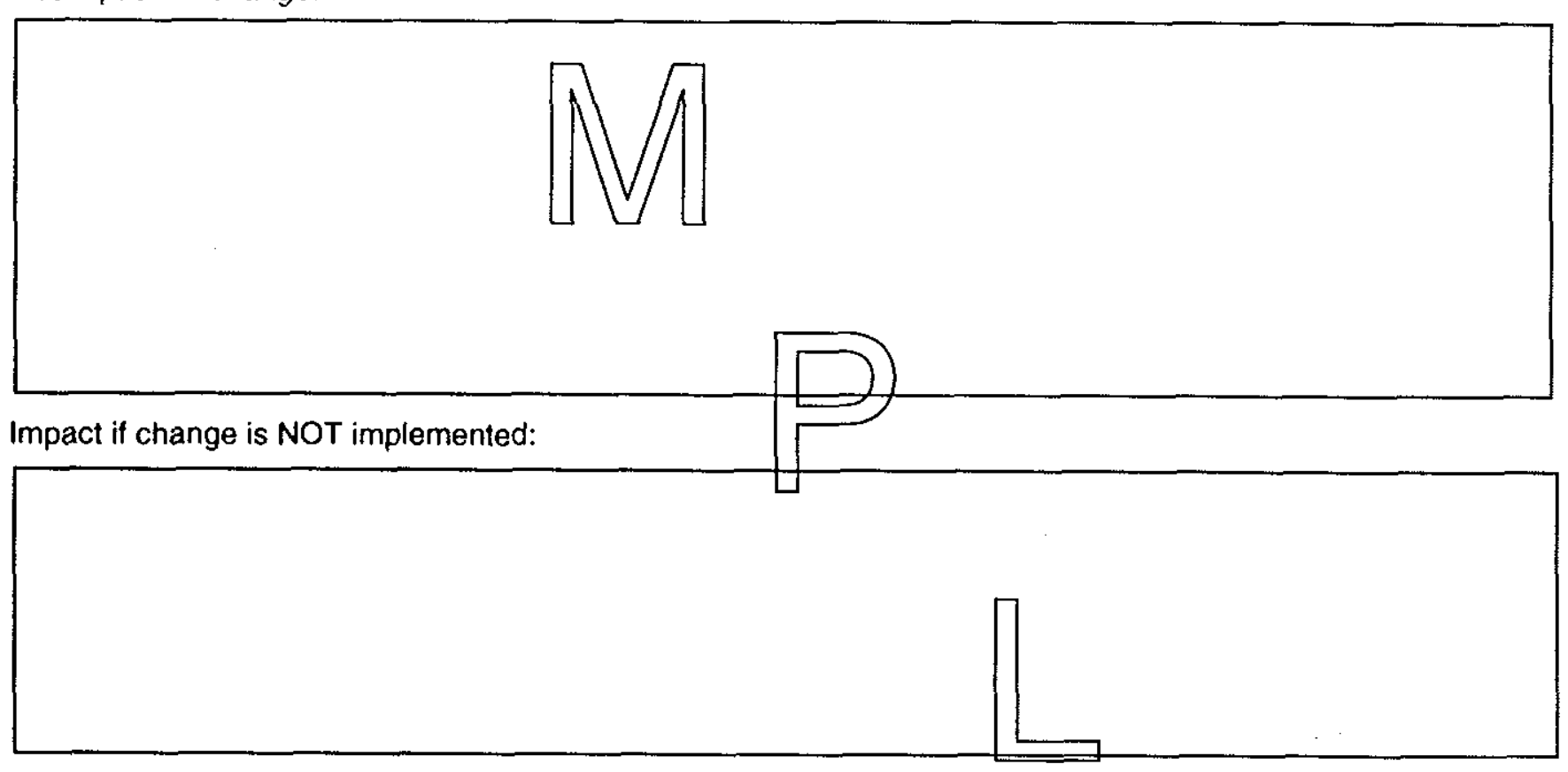

Completed by:

Date:

Reviewed by

Project EE

Date:

Recommendation(YES/NO):

Reviewed by

Project ME

Date:

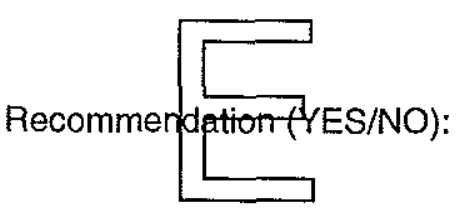

Recommendation (YES/NO):

Approved by:

Project Engineer

Date: 


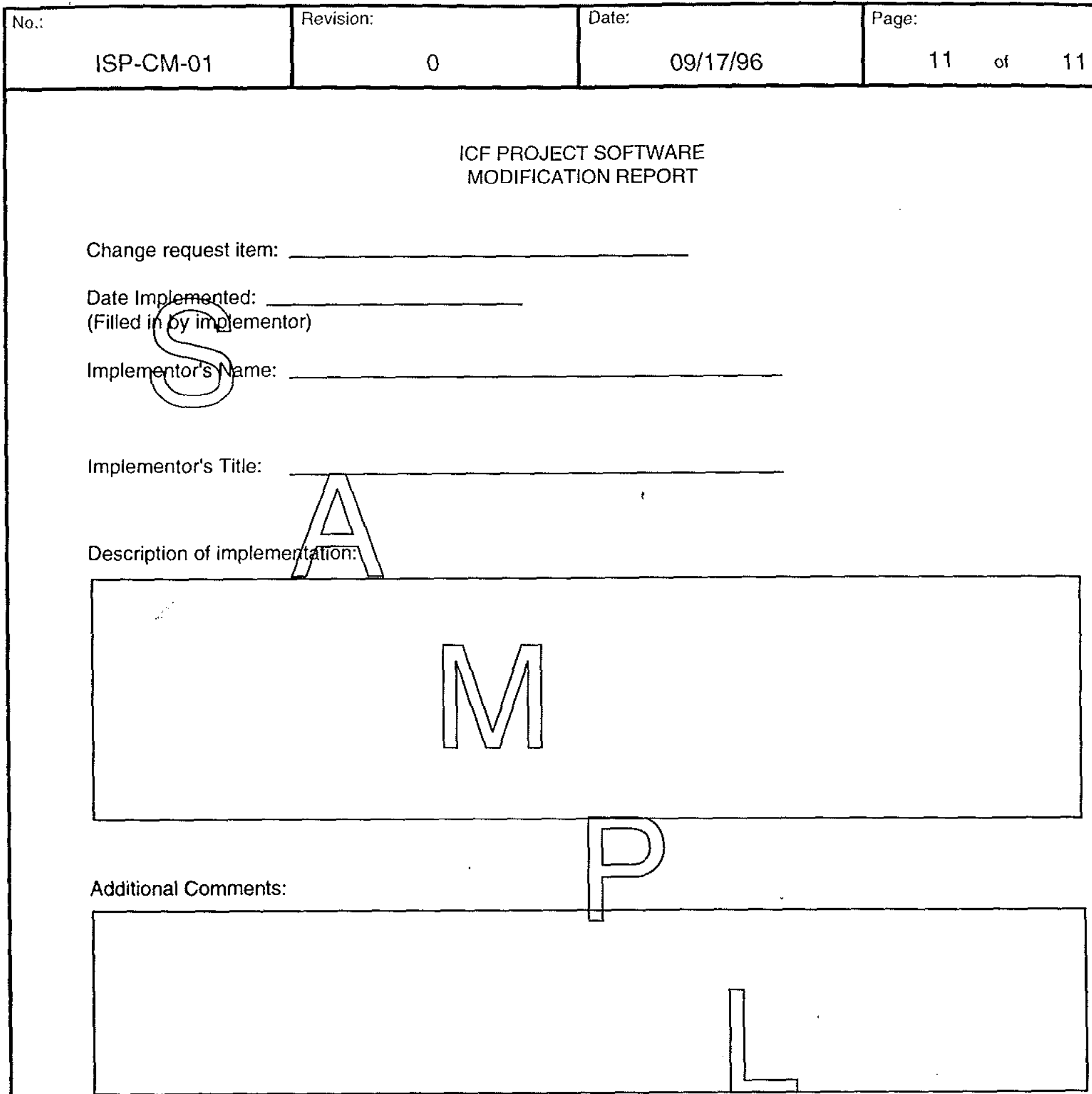

Time to complete (Person Days)

Software version after change

Completed by:

Date:

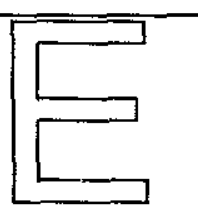


ISP-CM-01, Appendix A

CMS 96-054, System Test Plan and System Operation and Verification Test Procedure

(this appendix is 30 pages in length -- not including this cover page) 
C.MS 96-0.54

INTEGRATED CORROSION FACILITY

B-435 R-1020, 1048

System Test Plan and

System Operation and Verification Test Procedure

Prepared By:
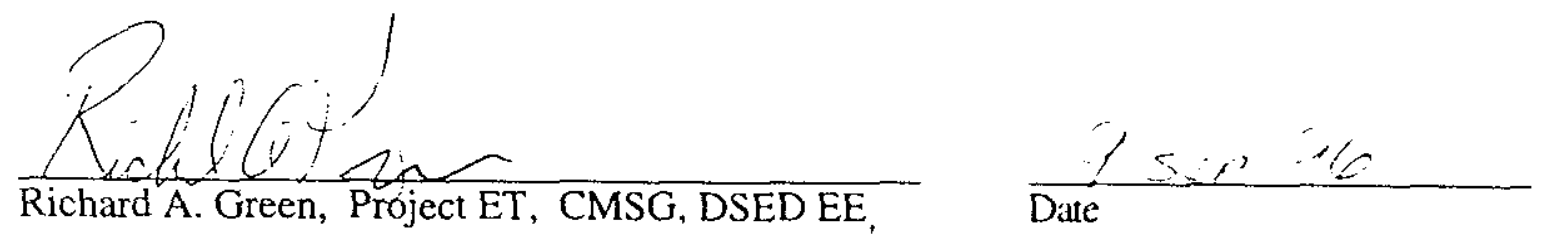

Reviewed By:

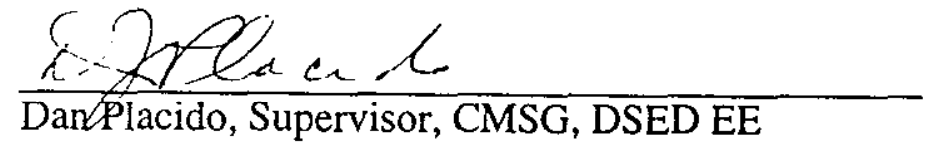

Approved By:
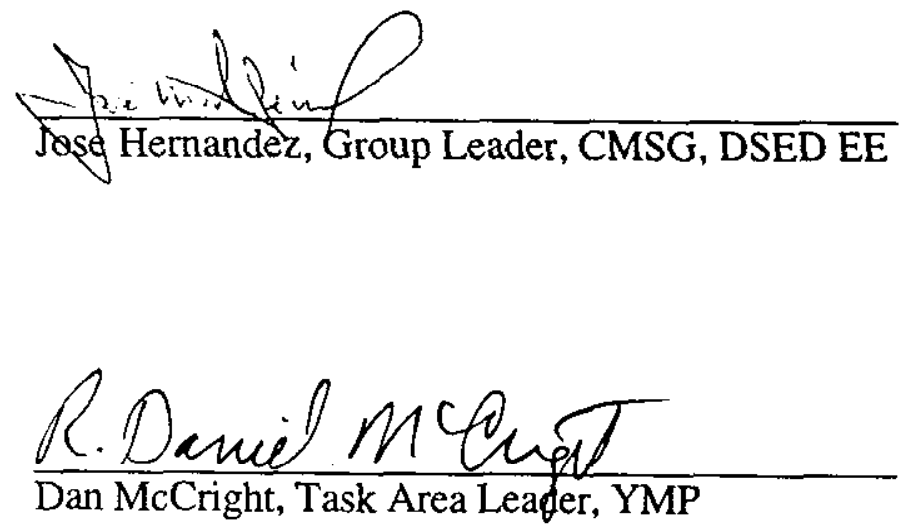
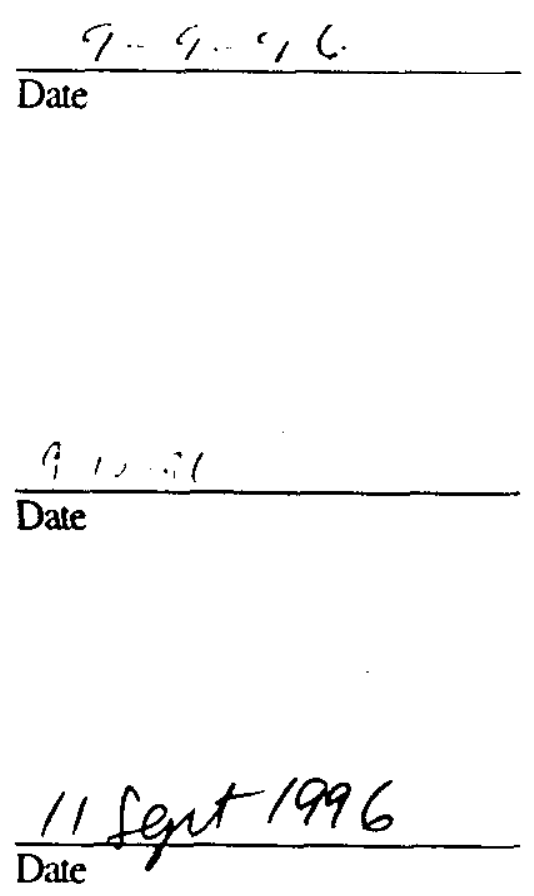

1 
1.1 PURPOSE

2.0 WIRING VERIFICATION

2.1 SCR CABINET

. .4

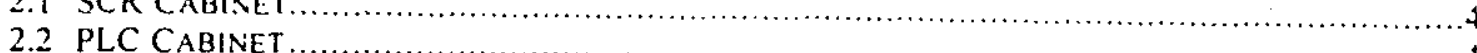

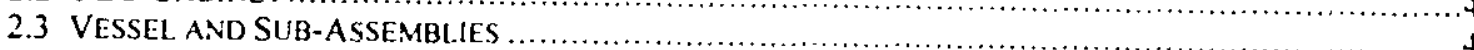

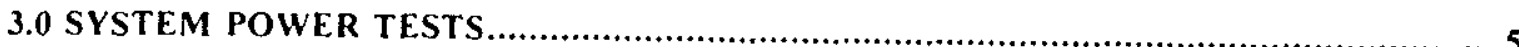

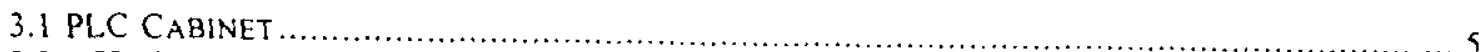

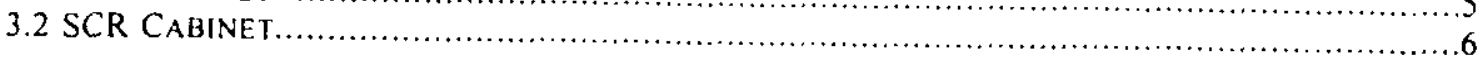

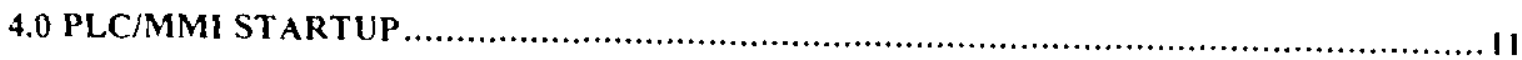

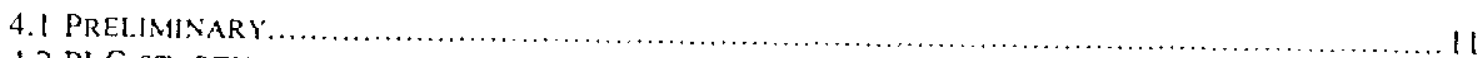

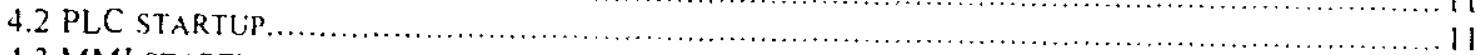

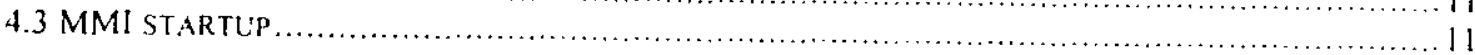

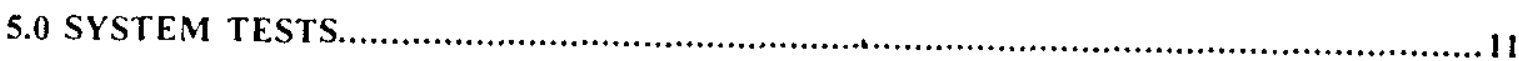

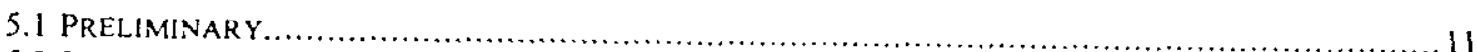

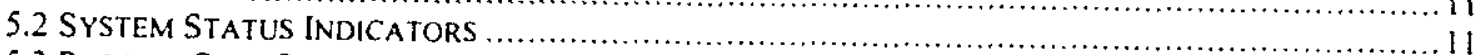

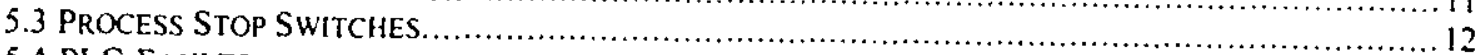

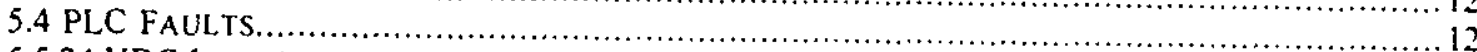

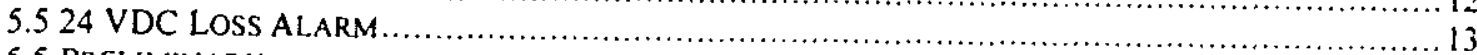

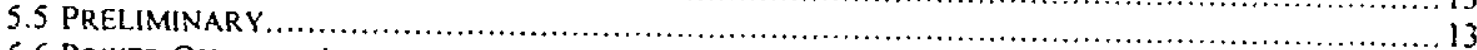

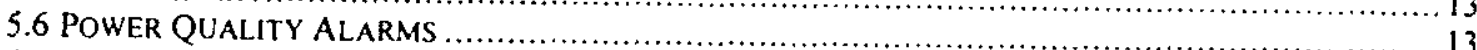

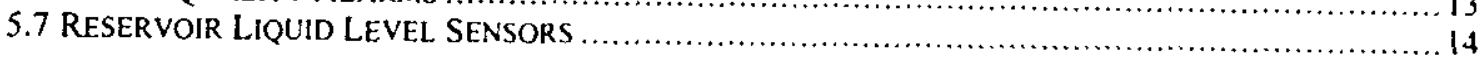

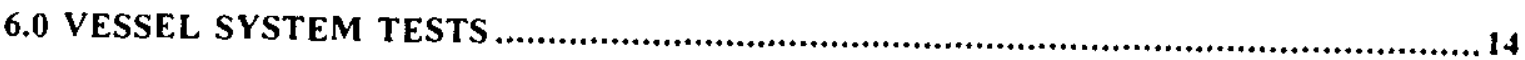

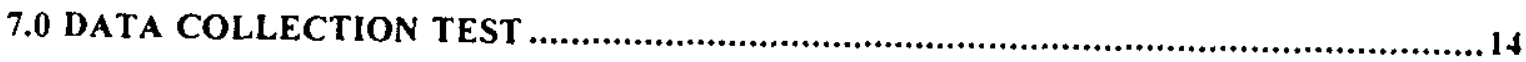

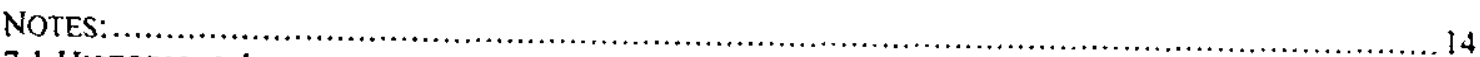

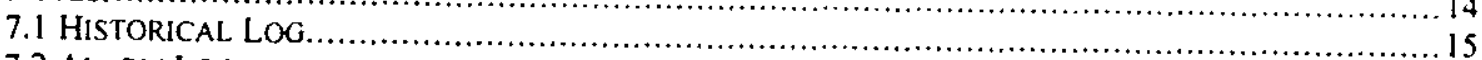

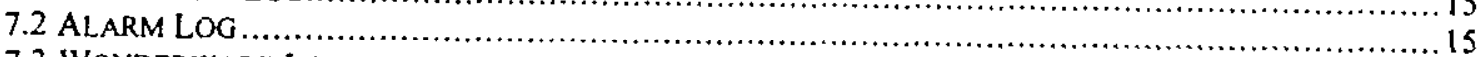

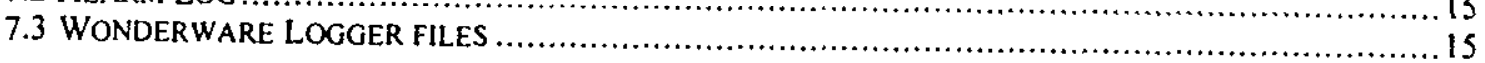

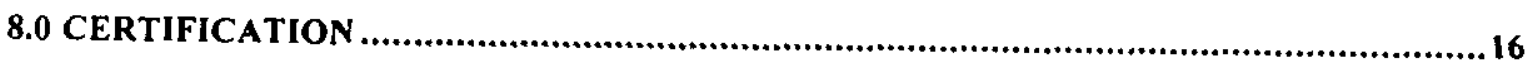

APPENDIX A

CORROSION VESSEL SYSTEM OPERATION AND VERIFICATION TEST PROCEDURE... 18

1.0 THERMOCOUPLE CALIBRATION .18

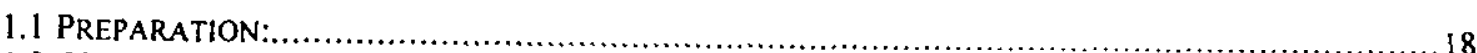

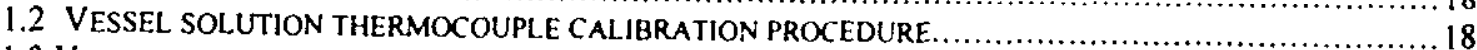

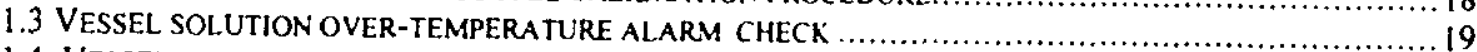

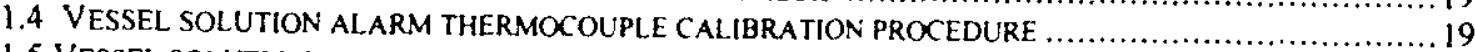

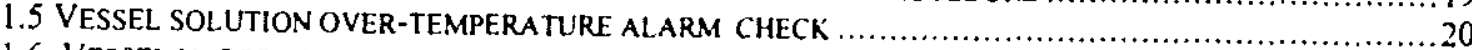

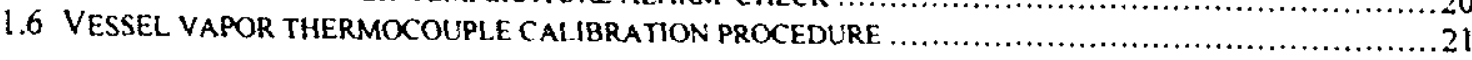

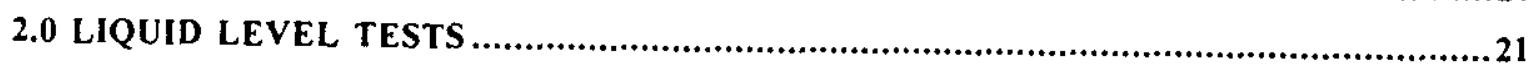

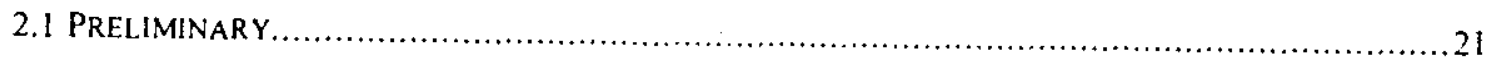


2.2 LKUTH LEVLL ALARNS - PHYSICAL CHECK

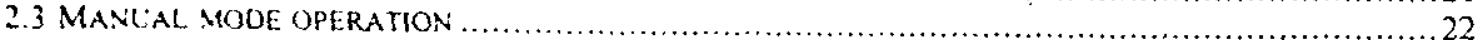

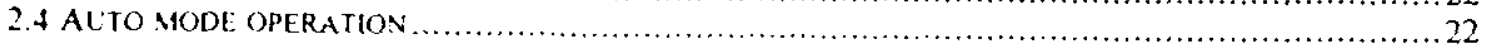

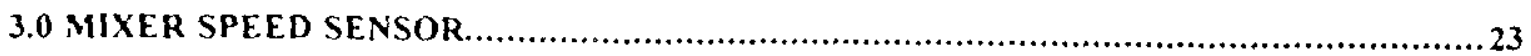

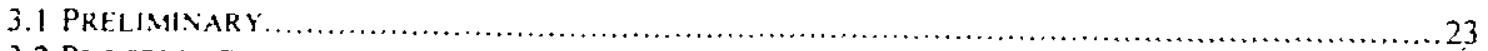

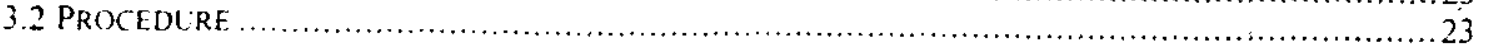

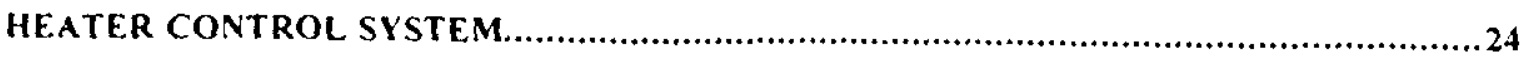

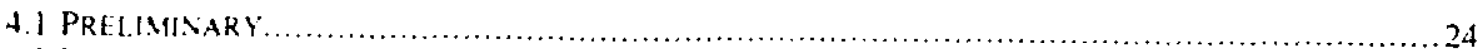

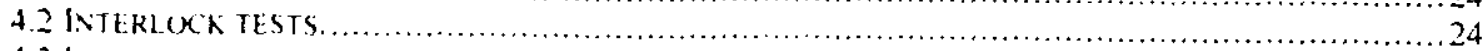

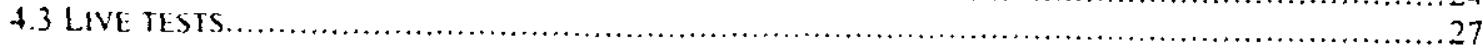

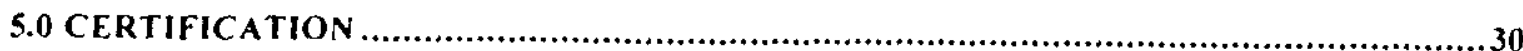




\title{
INTEGRATED CORROSION FACILITY
}

\author{
B-435 R-1020, 1048 \\ System Test Plan \\ and \\ System Operation and Verification Test Procedure
}

\subsection{General}

\subsection{Purpose}

This document defines the post-installation System Operation and Verification Tests of the hardware and software used in the monitoring and control and interlock system that supports the Integrated Corrosion Facility.

Note:

Only qualified Electronics Engineering personnel may perform the following tests. Personnel qualifications are at the discretion of the project support EE Supervisor or designated alternate.

\subsection{Wiring Verification}

\section{$2.1 \quad$ SCR Cabinet}

2.1.1 Refer to all active LEA96-2700 series drawings pertaining to the SCR Cabinet.

2.1.2 Verify that all wiring and component installations are completed according to the drawings listed above.

\section{$2.2 \quad$ PLC Cabinet}

2.2.1 Refer to all active LEA96-2700 series drawings pertaining to the PLC Cabinet.

2.2.2 Verify that all wiring and component installations are completed according to the drawings listed above.

2.3 Vessel and Sub-Assemblies 
2.3.1 Refer to all active LEA96-2700 series drawings pertaining to the PLC Cabinet.

2.3.2 Verify that all wiring and component installations are completed according to the drawings listed above.

\subsection{System Power Tests}

\section{NOTES:}

Warning: 480VAC is present within the SCR Cabinet and the heating system conduits. Ensure all enclosure covers are in place and that the SCR Cabinet doors are closed. Never work in or on this equipment alone.

Section 3 requires Fluke 77 or a multimeter with comparable specifications and features.

3.1 PLC Cabinet

\subsubsection{VAC Checks}

3.1.1.1 Tum on circuit breakers 594A6-25 (PLC 120 VAC) and 594A6-27 (24 VDC system power supply).

3.1.1.2 Using a multimeter, measure between terminals 1 and 2 (IN) of Phoenix Contact Surge Suppresser UAK 2-PE/S - Unit 1, verify that the reading is $120 \mathrm{VAC} \pm 5 \mathrm{VAC}$. Record the measured voltage.

VAC

3.1.1.3 Using a multimeter, measure between terminals 3 and 4 (OUT) of Phoenix Contact Surge Suppresser UAK 2-PE/S - Unit 1, verify that the reading is $120 \mathrm{VAC} \pm 5 \mathrm{VAC}$. Record the measured voltage.

VAC

3.1.1.4 Using a multimeter, measure between terminals 1 and 2 (IN) of Phoenix Contact Surge Suppresser UAK 2-PE/S - Unit 2, verify that the reading is $120 \mathrm{VAC} \pm 5 \mathrm{VAC}$. Record the measured voltage.

VAC

3.1.1.5 Using a multimeter, measure between terminals 3 and 4 (OUT) of Phoenix Contact Surge Suppresser UAK 2-PE/S - Unit 2, verify that the reading is $120 \mathrm{VAC} \pm 5 \mathrm{VAC}$. Record the measured voltage. 
3.1.1.6 Measure between terminals L1 and L2/N on PS 1 of PLC chassis 1 verify that the voltage is $120 \mathrm{VAC} \pm 5 \mathrm{VAC}$. Record the measured voltage.

VAC

3.1.1.7 Measure between terminals L1 and L2/N on PS1 of PLC chassis 2 verify that the voltage is $120 \mathrm{VAC} \pm 5 \mathrm{VAC}$. Record the measured voltage.

VAC

3.1.1.8 Measure between terminals L1 and L2/N on PS1 of PLC chassis 3 verify that the voltage is $120 \mathrm{VAC} \pm 5 \mathrm{VAC}$. Record the measured voltage.

VAC

3.1.1.9 Measure between terminals $\mathrm{L} 1$ and $\mathrm{L} 2 / \mathrm{N}$ on PS1 of PLC chassis 4 verify that the voltage is $120 \mathrm{VAC} \pm 5 \mathrm{VAC}$. Record the measured voltage.

VAC

3.1.1.10 Measure between input terminals $L$ and $N$ on PLC Cabinet PS1 (24 VDC power supply) verify that the voltage is $120 \mathrm{VAC} \pm 5 \mathrm{VAC}$. Record the measured voltage.

VAC

\subsubsection{VDC Check}

3.2.2.1 Measure the "+" and "-“ terminals of PLC Cabinet PS1 (24 VDC power supply). Verify that the output of PS1 is 24 VDC \pm .3 VDC. Record the measured voltage.

VDC

\subsection{SCR Cabinet}

\subsubsection{VAC Checks}

3.2.1.1 Turn on circuit breaker 561A1-2-40. This energizes the SCR Cabinet 480 to $208 / 120$ VAC transformer.

3.2.1.2 Turn on circuit breakers CB1, CB2, and CB3 in the SCR Cabinet.

3.2.1.3 Measure SCR Cabinet TB5 terminals 1-10, phase X with respect to neutral (located on TB5 terminals 31-60). Verify that the terminals read 120 VAC \pm 5 VAC. Record the measured voltage. 


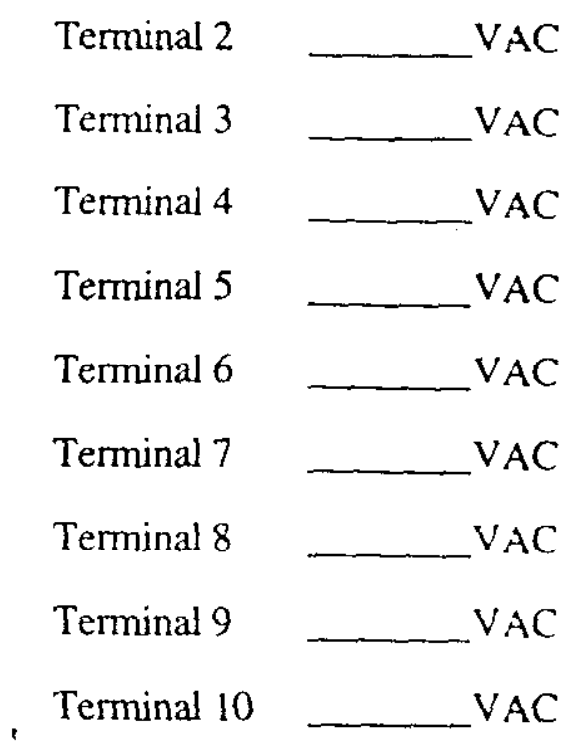

3.2.1.4 Measure SCR Cabinet TB5 terminals 11-20, phase Y, with respect to neutral (located on TB5 terminals $31-60$ ). Verify that the terminals read $120 \mathrm{VAC} \pm 5 \mathrm{VAC}$. Record the measured voltage.

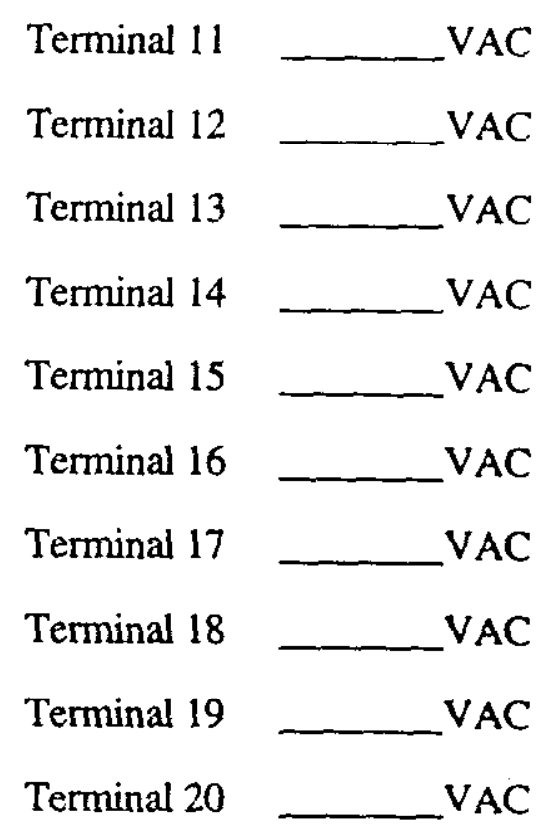

3.2.1.5 Measure SCR Cabinet TB5 terminals 21-30, phase $Z$, with respect to neutral (located on TB5 terminals 31-60). Verify that the terminals read $120 \mathrm{VAC} \pm 5 \mathrm{VAC}$. Record the measured voltage.

Terminal 21

Terminal 22

Terminal 23 VAC VAC VAC 


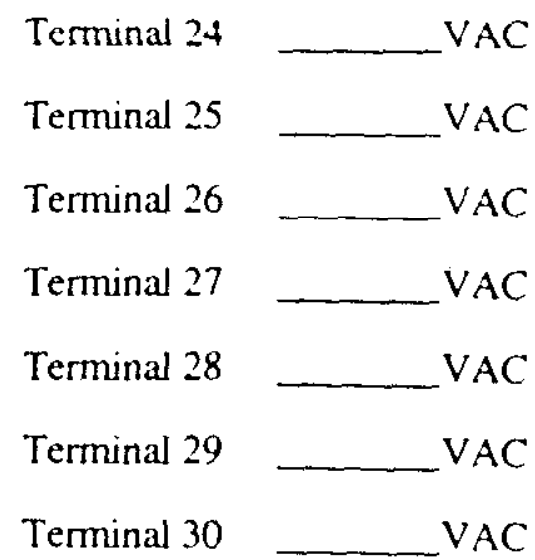

\subsubsection{Power Quality Monitor}

3.2.2.1 Inspect the AGASTAT power quality monitor located in the SCR Cabinet. The "Contacts Transferied" lamp should be on.

\subsubsection{VAC Checks}

3.2.3.1 For each installed system, one at a time, turn on the heater system 480 VAC circuit breaker located in Power Panels 561 Al-1, 561 Al-2, and 561 A1-3. Measure between terminals L1 and L2 of the contactor associated with that heating system.

For example, if heater system 1 were under test, measurements would be taken from $\mathrm{L} 1$ and $\mathrm{L} 2$ of contactor $\mathrm{CO}$.

3.2.3.2 Verify that the voltage reads $480 \mathrm{VAC} \pm 20 \mathrm{VAC}$

3.2.3.3 Record the measured voltage for each installed heater system.

1. Heater system number $1(\mathrm{CO} / \mathrm{L} 1$ and $\mathrm{L} 2)$ VAC

2. Heater system number $2(\mathrm{CO} 2 \mathrm{~L} 1$ and $\mathrm{L} 2)$ VAC

3. Heater system number $3(\mathrm{CO} 3 \mathrm{~L} 1$ and $\mathrm{L} 2)$ VAC

4. Heater system number $4(\mathrm{CO} 4 \mathrm{Ll}$ and $\mathrm{L} 2)$ VAC

5. Heater system number $5(\operatorname{CO} \mathrm{L} 1$ and $\mathrm{L} 2)$ VAC

6. Heater system number 6 (CO6 L1 and L2) VAC

7. Heater system number 7 (CO7 L1 and L2) VAC 
8. Heater system number $8(\mathrm{CO} \mathrm{LL}$ and $\mathrm{L} 2)$ VAC

9. Heater system number 9 (CO9 L1 and L2) VAC

10. Heater system number 10 (CO10 L1 and L2) VAC

11. Heater system number $11(\mathrm{CO} 11 \mathrm{~L} 1$ and L2) VAC

12. Heater system number 12 (CO12 L1 and L2) VAC

13. Heater system number $13(\mathrm{CO} 13 \mathrm{~L} 1$ and L2) VAC

14. Heater system number 14 (CO14 L1 and L2) VAC

15. Heater system number 15 (CO15 L1 and L2) VAC

16. Heater system number $16(\mathrm{CO} 16 \mathrm{~L} 1$ and $\mathrm{L} 2)$ VAC

17. Heater system number $17(\mathrm{CO} 17 \mathrm{LI}$ and $\mathrm{L} 2)$ VAC

18. Heater system number 18 (CO18 L1 and L2) VAC

19. Heater system number 19 (CO19 L1 and L2) VAC

20. Heater system number $20(\mathrm{CO} 20 \mathrm{Ll}$ and L2) VAC

21. Heater system number 21 (CO21 L1 and L2) VAC

22. Heater system number $22(\mathrm{CO} 22 \mathrm{~L} 1$ and L2) VAC

23. Heater system number 23 (CO23 L1 and L2) VAC

24. Heater system number 24 (CO24 L1 and L2) VAC

25. Heater system number 25 (CO25 L1 and L2) VAC 
26. Heater system number 26 (CO26 L1 and L2) VAC

27. Heater system number 27 (CO27 L1 and L2) VAC

28. Heater system number 28 (CO28 LI and L2) VAC

29. Heater system number 29 (CO29 L1 and L2) VAC

30. Heater system number 30 (CO30 L1 and L2) VAC

31. Heater system number 31 (CO31 L1 and L2) VAC

32. Heater system number 32 (CO32 L1 and L2) VAC

33. Heater system number 33 (CO33 L1 and L2) VAC

34. Heater system number 34 (CO34 L1 and L2) VAC

35. Heater system number 35 (CO35 L1 and L2) VAC

36. Heater system number 36 (CO36 L1 and L2) VAC

37. Heater system number 37 (CO37 L1 and L2) VAC

38. Heater system number 38 (CO38 L1 and L2) VAC

39. Heater system number 39 (CO39 LI and L2) VAC

40. Heater system number 40 (CO40 LI and L2) VAC

41. Heater system number 41 (CO41 L1 and L2) VAC

42. Heater system number 42 (CO42 L1 and L2) VAC

43. Heater system number 43 (CO43 LI and L2) VAC 


\subsection{PLC/MMI Startup}

4.1 Preliminary

- Ensure that circuit breakers 594A6-24 (120 VAC for PLC racks) and 594A6-27 (120 VAC for 24 VDC power supply) are ON.

- Turn on the MMI computer by pressing the "Power" switch. Log on as "EE" check with the Workstation Administrator for the current EE password.

\subsection{PLC startup}

4.2.1 Turn the ON/OFF switch on the power supplies for PLC Racks 2, 3 and 4 to the $\mathrm{ON}$ position. Verify that the green power indicator is lit for each power supply.

4.2.2 Ensure the PLC Key switch on the 5/40 PLC in Rack 1 is in the "REM" (remote) position. Tum the ON/OFF switch on the power supply for PLC Rack I to the ON position. Verify that the green power indicator is lit.

Immediately after energizing, the PLC will start and complete a boot sequence and then, begin to run the ICF program.

\subsection{MMI startup}

4.3.1 Start the MMI program by selecting the "ICF" program icon within the ICF program group. This starts "Wonderware View" and associated support programs - these programs serve as the MMI.

4.3.2 Ensure the programs start without error. For details regarding the MMI and its use please refer to the ICF user's manual.

\subsection{System Tests}

These tests check the hardware and the software systems used in the ICF.

\subsection{Preliminary}

5.2 System Status Indicators

5.2.1 On the MMI, select the "Maintenance" window.

5.2.1.1 Press the System Status Indicator - Lamp Test button.

5.2.1.2 Verify that the red, yellow and green lamps are illuminated on the System Status Indicators located in Rooms 1020 and 1048. 


\subsubsection{Release the lamp test button.}

\subsection{Process Stop Switches}

5.3.1 Induce a Process Stop by pressing the "Process Stop" switch located in Room 1020.

5.3.2 Verify that the System Status Indicator - red (Major Fault) indicator is illuminated and that the green (No Fault) indicator is extinguished.

Verify that the Process Stop Alarm is flashing on the MMI.

Verify that the "Alarms" window displays a "YS1" alarm.

5.3.3 Reset the Process Stop switch by pulling it out until it snaps into the ready position.

5.3.4 Verify that the System Status Indicator - red (Major Fault) indicator is extinguished and that the green (No Fault) indicator is illuminated.

Verify that the Process Stop Alarm is not visible on the MMI.

Verify that the "YS1" alarm has cleared from the "Alarms" window.

5.3.1 Induce a Process Stop by pressing the "Process Stop" switch located in Room 1048.

5.3.2 Verify that the System Status Indicator - Red (Major Fault) indicator is illuminated and that the green (No Fault) indicator is extinguished.

Verify that the Process Stop Alarm is flashing on the MMI.

Verify that the "Alarms" window displays a "YS1" alarm.

5.3.3 Reset the Process Stop switch by pulling it out until it snaps into the ready position.

5.3.4 Verify that the System Status Indicator - red (Major Fault) indicator is extinguished and that the green (No Fault) indicator is illuminated.

Verify that the Process Stop Alarm is not visible on the MMI.

Verify that the "YS1" alarm has cleared from the "Alarms" window.

\subsection{PLC Faults}

5.4.1 Assert a PLC fault by turning off the power supply to PLC chassis 4 .

5.4.2 Verify that the System Status Indicator - red (Major Fault) indicator is illuminated and that the green (No Fault) indicator is extinguished. Verify a PLC fault is visible on the MMI.

Verify that the "Alarms" window displays a "PLC_FAULT" alarm.

\subsubsection{Reset the PLC fault.}

5.4.3.1 Turn on the power supply for PLC chassis 4.

5.4.3.2 On PLC processor, turn the key from "REM" to "RUN" and back to "REM". This should restart the system. 
5.4.4 Verify that the System Status Indicator - red (Major Fault) indicator is extinguished and that the green (No Fault) indicator is illuminated.

Verify the PLC Fault indicator is not visible on the MMI.

Verify the "PLC Fault" alarm has cleared from the "Alarms" window.

\section{$5.5 \quad 24$ VDC Loss Alarm}

5.5 Preliminary

Ensure that circuit breaker 594A6-27 is on

Ensure there are no active system alarms.

5.5.1 Simulate a 24 VDC failure by turning circuit breaker 594A6-27 to the "OFF" position.

5.5.2 Verify that the System Status Indicator - red (Major Fault) indicator is illuminated and that the green (No Fault) indicator is extinguished.

Verify a "24 VDC Loss" alarm is visible on the MMI.

Verify that the "Alarms" window displays a "VAl" alarm.

5.5.3 Clear the 24 VDC Loss alarm by turning circuit breaker 594A6-27 to the "ON" position.

5.5.4 Verify that the System Status Indicator - red (Major Fault) indicator is extinguished and that the green (No Fault) indicator is illuminated.

Verify the 24 VDC Loss alarm is not visible on the MMI.

Verify the "VA1" alarm has cleared from the "Alarms" window.

NOTE:

Warning: 480VAC is present within the SCR Cabinet and the heating system conduits. Ensure all enclosure covers are in place and that the SCR Cabinet doors are closed. Never work in or on this equipment alone.

\subsection{Power Quality Alarms}

\subsubsection{Preliminary}

Ensure that circuit breaker 561A1-2-40 is turned on.

Ensure that circuit breakers SCR Cabinet $\mathrm{CB} 1, \mathrm{CB} 2$ and $\mathrm{CB} 3$ are on.

Ensure there are no active system alarms

5.6.2 Inspect the AGASTAT power quality monitor located in the SCR Cabinet. The "Contacts Transferred" lamp should be on.

5.6.3 Simulate a power phase loss by switching CB1 located in the SCR Cabinet to the "OFF" position.

5.6.4 Verify that the System Status Indicator - red (Major Fault) indicator is illuminated and that the green (No Fault) indicator is extinguished.

Verify a "480 Loss" alarm is visible on the MMI.

Verify that the "Alarms" window displays a "VA2" alarm. 
5.6.5 Clear the fault by switching SCR Cabinet CB 1 to the "ON" position.

5.6.6 Verify that the System Status Indicator - red (Major Fault) indicator is extinguished and that the green (No Fault) indicator is illuminated.

Verify the 480 VAC Loss indicator is not visible on the MMI.

Verify the "VA2" alarm has cleared from the "Alarms" window.

\subsection{Reservoir Liquid Level Sensors}

5.7.1 Preliminary

Ensure Make-up water reservoir is full.

Ensure there are no active system alarms

5.7.2 Observe the MMI, (the reservoir status indicators are on the summary page) ensure that the reservoir status indicators are green.

5.7.3 Check the upper limit switch by draining the reservoir until the water level is below the upper level sensor.

NOTE:

The reservoir can be drained by pumping, opening the drain valve, or by opening the fill valves to a vessel.

5.7.4 Check the MMI, verify that the "Upper Limit" indicator has changed color from green to gray. Ensure the "Add Solution" and "Low Limit" status are green.

5.7.5 Drain the reservoir to a level just below the middle level sensor.

5.7.6 Check the MMI, verify that the upper limit indicator is gray and that the "Add Solution" indicator has changed from green to flashing yellow. Ensure the "Low Limit" indicator is green.

5.7.7 Drain the reservoir to a level below the trip-line on the low sensor.

5.7.8 Check the MMI, verify that the upper limit indicator is gray, the "Add Solution" indicator is flashing yellow and that the "Low Limit" indicator has changed from green to flashing red.

\subsection{Vessel System Tests}

6.1 Each vessel system operates the same as the others therefore, one procedure can be used for all vessels. Use the "Corrosion Vessel System Operation and Verification Test Procedure", in Appendix A, for each vessel system to be used. Record verification test procedure results on the form. Place the completed forms with this document in the Project QA file.

\subsection{Data Collection Test}

Notes: 
This procedure requires some knowledge of Wonderware InTouch software. Refer to the InTouch user's guide for extracting data from the InTouch log files.

The Historical Log files are in a binary format and must be converted to another format prior to review.

\subsection{Historical Log}

7.1.1 The Historical Log files are identified by the date followed by a ".lgh" (960619.lgh). The location of the log files is specified within the InTouch configuration. The Historical Log files are in a binary format and must be converted to another format prior to review.

7.1.2 Review the most recent historical $\log$ file. Ensure that data is available for the vessels that were under test and that the data is suitable format for later analysis.

\subsection{Alarm Log}

7.2.1 The Alarm Log files are identified by the date followed by ".alg" (960619.alg). The location of the log files is specified within the InTouch configuration. The alarm log files are text files and can be viewed with a text editor or viewer (Windows Notepad, or Word)

7.2.2 Review the most recent alarm log file. Ensure that the alarms generated during the procedure are present in the log.

\subsection{Wonderware Logger files}

7.3.1 The Wonderware Logger files are identified by the date followed by ".aeh" (960619.aeh). The location of the log files is specified within the InTouch configuration. The WW Logger files are text files and can be viewed with a text editor or viewer (Windows Notepad, or Word).

7.3.2 Review the most recent WW Logger file. Ensure that the logger has recorded Wonderware events and DDE conversations. 


\subsection{Certification}

I certify that the Integrated Corrosion Facility electronics system has passed all requirements set by the procedure listed above.

Comments:

Name

Signature

Date 
Appendix A .

Corrosion Vessel System Operation and Verification Test Procedure 


\section{Corrosion Vessel System Operation and Verification Test Procedure}

\section{Vessel System}

\section{NOTES:}

The PLC and MMI systems must be in an operational state with no faults prior to starting these checks.

This procedure must be complete prior to placing each vessel system into operation.

Only qualified Electronics Engineering personnel may perform the following tests. Personnel qualifications are at the discretion of the project support EE Supervisor or designated alternate.

The "\#" character will appear throughout the procedure, this character will represent the number of the vessel under test. For example, if Vessel System 18 is being tested, the "\#" character will represent the number " 18 ".

\subsection{Thermocouple Calibration}

1.1 Preparation:

- Plug in and turn on a calibrated thermocouple simulator and allow 20 minutes warm-up (or the manufacture's recommended warm-up time). Set the simulator to simulate a type "T" thermocouple.

- On the MMI, set the over-temperature setpoint for the vessel under test to $94^{\circ} \mathrm{C}$.

- Tum on the channel for the vessel under test by pressing the channel on/off button on the MMI. Verify that the channel is on.

1.2 Vessel solution thermocouple calibration procedure

1.2.1 Connect calibrated thermocouple simulator to TB1-1 (+) TB1-2 (-) of the Flowline thermocouple junction box located on the vessel lid. This will simulate thermocouple TE \#-1 (Vessel Solution).

NOTE:

If a thermocouple is already connected to the TBI then remove one thermocouple wire $(+)$ prior to connecting the thermocouple calibrator. Failure to remove the wire will result in erroneous calibration readings. 
1.2.2 Set the simulator to $0^{\circ} \mathrm{C}$.

1.2.3 Observe the MMI. Record the reading for TE \#-I (Vessel Solution).

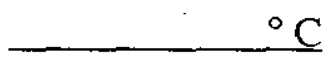

1.2.4 Verify that the $\mathrm{MMI}$ reading for $\mathrm{TE} \#-1$ (Vessel Solution) is $0^{\circ} \mathrm{C} \pm .8^{\circ} \mathrm{C}$.

1.2.5 Set the simulator to $60^{\circ} \mathrm{C}$.

1.2.6 Observe the MMI. Record the reading for TE\#-1 (Vessel Solution).

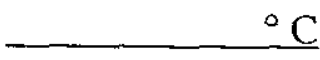

1.2.7 Verify that the MMI reading for TE \#-1 (Vessel Solution) is $60^{\circ} \mathrm{C} \pm .8^{\circ} \mathrm{C}$.

1.2.8 Set the simulator to $90^{\circ} \mathrm{C}$.

1.2.9 Observe the MMI. Record the reading for TE \#-1 (Vessel Solution).

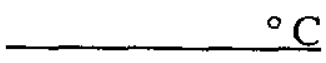

1.2.10 Verify that the MMI reading for TE \#-1 (Vessel Solution) is $90^{\circ} \mathrm{C} \pm .8^{\circ} \mathrm{C}$.

1.3 Vessel solution over-temperature alarm check

1.3.1 Set the simulator to $95^{\circ} \mathrm{C}$.

1.3.2 Observe the MMI, verify that the "HIGH TEMPERATURE" alarm is present. Verify that a "TAH_VESSEL\#" alarm is present in the "Alarms" window.

1.3.3 Check the system status indicator. Verify that the "MAJOR FAULT" (red indicator) is illuminated and that the "NO FAULTS" (green indicator) is extinguished.

1.3.4 Set the simulator to $90^{\circ} \mathrm{C}$.

1.3.5 Press the "Alarm Reset" switch on the MMI for the vessel system under test.

1.3.6 Observe the MMI, verify that the "HIGH TEMPERATURE" alarm is extinguished. Verify that the "TAH_VESSEL\#" is not present in the "Alarms" window.

1.3.7 Check the system status indicator. Verify that the "NO FAULTS" (green indicator) is illuminated and that the MAJOR FAULT" (red indicator) is extinguished.

1.4 Vessel solution alarm thermocouple calibration procedure 
1.4.1 Connect calibrated thermocouple simulator to the vessel TB 1-3(+) TB 1-4 (-) of the Flowline thermocouple junction box located on the vessel lid. This will simulate thermocouple TE\#-2 (Vessel Solution Alarm).

1.4.2 Set the simulator to $0^{\circ} \mathrm{C}$.

1.4.3 Observe the MMI. Record the reading for TE \#-2 (Vessel Solution Alarm).

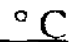

1.4.4 Verify that the MMI reading for TE\#-2 (Vessel Solution Alarm) is $0^{\circ} \mathrm{C} \pm .8^{\circ} \mathrm{C}$.

1.4.5 Set the simulator to $60^{\circ} \mathrm{C}$.

1.4.6 Observe the MMI. Record the reading for TE \#-2 (Vessel Solution Alarm).

${ }^{\circ} \mathrm{C}$

1.4.7 Verify that the MMI reading for TE \#-2 (Vessel Solution Alarm) is $60^{\circ} \mathrm{C} \pm .8$ ${ }^{\circ} \mathrm{C}$.

1.4.8 Set the simulator to $90^{\circ} \mathrm{C}$.

1.4.9 Observe the MMI. Record the reading for TE \#-2 (Vessel Solution Alarm).

${ }^{\circ} \mathrm{C}$

1.4.10 Verify that the MMI reading for TE \#-2 (Vessel Solution Alarm) is $90^{\circ} \mathrm{C} \pm .8$ ${ }^{\circ} \mathrm{C}$.

1.5 Vessel solution over-temperature alarm check

1.5.1 Set the simulator to $95^{\circ} \mathrm{C}$.

1.5.2 Observe the MMI, verify that the "HIGH TEMPERATURE" alarm is present. Verify that a "TAH_VESSEL\#" alarm is present in the "Alarms" window.

1.5.3 Check the system status indicator. Verify that the "MAJOR FAULT" (red indicator) is illuminated and that the "NO FAULTS" (green indicator) is extinguished.

1.5.4 Set the simulator to $90^{\circ} \mathrm{C}$.

1.5.5 Press the "Alarm Reset" switch on the MMI for the vessel system under test.

1.5.6 Observe the MMI, verify that the "HIGH TEMPERATURE" alarm is extinguished. Verify that the "TAH_VESSEL\#" is not present in the "Alarms" window. 
1.5.7 Check the system status indicator. Verify that the "NO FAULTS" (green indicator) is illuminated and that the MAJOR FAULT" (red indicator) is extinguished.

1.6 Vessel vapor thermocouple calibration procedure

1.6.1 Connect calibrated thermocouple simulator to the vesse I TB 1-5 (t) TB 1-6 (-) of the Flowline thermocouple junction box located on the vessel lid. This will simulate thermocouple TE\#-3 (Vessel Vapor).

1.6.2 Set the simulator to $0^{\circ} \mathrm{C}$.

1.6.3 Observe the MMI. Record the reading for TE \#-3 (Vessel Vapor).

1.6.4 Verify that the MMI reading for TE \#-3 (Vessel Vapor) is $0^{\circ} \mathrm{C} \pm .8^{\circ} \mathrm{C}$.

1.6.5 Set the simulator to $60^{\circ} \mathrm{C}$.

1.6.6 Observe the MMI. Record the reading for TE \#-3 (Vessel Vapor).

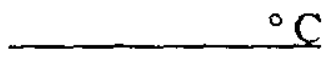

1.6.7 Verify that the MMI reading for TE \#-3 (Vessel Vapor) is $60^{\circ} \mathrm{C} \pm 8^{\circ} \mathrm{C}$.

1.6.8 Set the simulator to $90^{\circ} \mathrm{C}$.

1.6.9 Observe the MMI. Record the reading for TE \#-3 (Vessel Vapor).

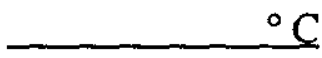

1.6.10 Verify that the MMI reading for TE $\#-3$ (Vessel Vapor) is $90^{\circ} \mathrm{C} \pm .8^{\circ} \mathrm{C}$.

\subsection{Liquid Level Tests}

\subsection{Preliminary}

- Ensure the vessel is filled with DI solution up to the setpoint level switch LSM_\# (the middle liquid level switch).

- Set the vessel fill mode switch on the MMI to "Manual Fill" mode.

- Verify that the channel for the vessel under test is on.

- Ensure there are no alarms.

2.2 Liquid Level Alarms - physical check 


\subsubsection{Test for high level a arm}

2.2.1.1 Fill vessel until the liquid level is just above the level set line on the high liquid level switch.

2.2.1.2 Verify a high liquid level (LSH_ALARM_\#) alarm on the MMI. Ensure. that the alarm is also present on the "Alarms" window.

2.2.1.3 Pump vessel solution to a level below the level set line on the high liquid level switch.

2.2.1.4 Press the "Alarm Reset" button for the vessel under test. Ensure the high liquid level alarm ceases.

2.2.2 Test for low liquid level alarm

2.2.2.1 Pump the solution out of the vessel until the liquid level is just below the level set line on the low liquid level switch (LSL\#).

2.2.1.2 Verify a low liquid level (LSL_ALARM_\#) alarm on the MMI. Ensure that the alarm is also present on the "Alarms" window.

2.2.2.3 Add vessel solution until the vessel level is above the low liquid level switch and below the setpoint liquid level switch.

2.2.2.4 Press the "Alarm Reset" button for the vessel under test. Ensure the low liquid level alarm ceases.

\subsubsection{PLC Fault interlock}

It is not practical to assert a PLC fault to test the channel interlocks. This would require the a PLC reboot for each fault asserted. Therefore, a logic check is required.

2.2.3.1 Refer to the Level control section in the PLC program (ladder logic program) documentation. Verify that a "Normally Closed" PLC Fault bit is in the interlock rung for the vessel under test.

\subsection{Manual mode operation}

\subsubsection{Verify the vessel fill mode switch is set to "Manual".}

\subsubsection{Press the "Fill" button on the MMI.}

2.3.3 Ensure the make-up water valves open by observing liquid flowing into the vessel.

2.3.4 Press the "Stop Fill" button on the MMI.

2.3.5 Ensure that the make-up water valves close and liquid is not flowing into the vessel.

\subsection{Auto mode operation}


2.4.1 Switch into auto mode by pressing the "Auto Fill" mode button on the MMI.

2.4.2 Ensure the vessel fills and maintains the liquid level at the trip line on the setpoint liquid level switch (LSM_\#).

2.4.3 Induce a high liquid level alarm by placing a cup of DI solution under the high limit liquid level switch (LSH\#) - gently lift the cup until the cup solution level is above the trip line on the sensor.

2.4.4 Verify the MMI displays a high liquid level alarm and that the solution fill system has switched to the "Manual" mode and that the fill valves are closed.

2.4.5 Clear the high solution level alarm by pressing alarm reset button on the MMI.

2.4.6 Set the vessel fill system to the "Auto" mode and ensure there are no alarms.

2.4.7 Induce a low liquid level alarm by removing the retum lead from TB1-6 in the Flowline Level sensor housing.

2.4.8 Verify the MMI displays a low solution level alarm and that the solution fill system has switched to the "Manual" mode and that the fill valves are closed.

2.4.9 Reinstall the lead on TB 1-6 in the Flowline Level sensor housing.

2.4.10 Clear the low solution alarm by pressing alarm reset button on the MMI. Ensure the system does not revert to the auto fill mode.

2.4.11 Set the vessel fill system to the "Auto" mode and ensure there are no alarms.

2.4.12 Assert a process stop command by pressing the "Process Stop" Switch.

2.4.13 Verify the MMI displays a "Process Stop" alarm and that the solution fill system has switched to the "Manual" mode and that the fill valves are closed.

2.4.14 Remove the Process Stop by pulling the stop switch out. Verify that the process stop alarm is extinguished.

\subsection{Mixer Speed Sensor}

\section{1 Preliminary}

3.1.1 Verify that the channel for the vessel under test is on.

3.1.2 Verify that the DCX Mixer Speed Controller is on and the speed potentiometer is set above $20 \%$ as seen on the controller front panel.

3.1.3 Verify there are no PLC or MMI related alarms.

\subsection{Procedure}

3.2.1 Observe the MMI, ensure there are no alarms on the on the screen for the vessel under test. 
3.2.2 Set the speed potentiometer DCX Mixer Speed Controller to 0\%.

3.2.3 Observe the MMI.

3.2.4 Verify the "MIXER STOPPED" alarm is flashing.

3.2.5 Verify the SSA\# alarm is displayed on the alarms panel (\# is the vessel under test).

3.2.6 Verify the amber lamp (minor fault) on the System Status Indicator is illuminated.

3.2.7 Set the speed potentiometer DCX Mixer Speed Controller to 20\%.

3.2.8 Ensure that all alarms observed in steps 3.2.3.1-3 are cleared.

\section{Heater Control System}

4.1 Preliminary

NOTE:

Warning: 480VAC is present within the SCR Cabinet and the heating system conduits. Ensure all enclosure covers are in place and that the SCR Cabinet doors are closed. Never work in or on this equipment alone.

4.1.1 The PLC system and MMI system should be up and running with no active faults.

4.1.2 Ensure the Mixer motor is on and rotating.

4.1.3 Verify the vessel solution level is close to the setpoint liquid level switch LSM\# (Between LSH\# and LSL\#.

4.1.4 Ensure Circuit Breaker 561 A1____ (480 VAC for vessel \#) is off.

4.1.5 Verify that Circuit Breakers 561 A1-2 and 561A1-2-40 (SCR system 208/120 VAC) are on.

4.2 Interlock tests.

\subsubsection{Start-up interlocks.}

4.2.1.1 On the MMI, turn on the channel for the vessel under test.

4.2.1.2 Verify that the heating system is off, in "Manual" mode and set to $0 \%$ power.

4.2.1.3 Turn on the heating system by pressing the "Heat On" button on the MMI.

4.2.1.4 Verify that the orange "Heat On" indicator is lit, and CO\# is energized (\# is the vessel under test). 
4.2.1.5 Turn off the heating system by pressing the "Heat OFF" button on the MMI.

4.2.2 Over-temperature alarm/interlocks.

4.2.2.1 Turn on the heating system by pressing the "Heat On" button on the MMI.

4.2.2.2 Verify that the orange "Heat On" indicator is lit, and CO\# is energized.

4.2.2.3 Set a temperature in the over-temperature alarm setpoint to a level $1{ }^{\circ} \mathrm{C}$ below the solution temperature. For example, if the solution temperature is $22{ }^{\circ} \mathrm{C}$ then the over-temperature setpoint should be $21^{\circ} \mathrm{C}$.

4.2.2.4 Verify the over-temperature alarm is visible on the MMI. Ensure that the orange "Heat On" indicator is extinguished, and the light blue "Heat Off: indicator is lit and $\mathrm{CO \#}$ is de-energized.

4.2.2.5 Set the over-temperature alarm setpoint to $94^{\circ} \mathrm{C}$.

4.2.2.6 Press the "Alarm Reset" button and verify the over-temperature alarm extinguishes.

\subsubsection{Solution level interlocks}

4.2.3.1 Turn on the heating system by pressing the "Heat On" button on the MMI.

4.2.3.2 Verify that the orange "Heat On" indicator is lit, and CO\# is energized.

4.2.3.3 Induce a solution level high alarm by placing a cup filled with solution under the high level switch, LSH\#. Gently raise the cup until the solution in the cup is above the switch-trip line.

4.2.3.4 Lower and remove the cup used in step 4.2.3.3.

4.2.3.5 Verify solution high alarm is visible on the MMI. Ensure that the orange "Heat On" indicator is extinguished, and the light blue "Heat Off: indicator is lit and $\mathrm{CO} \#$ is de-energized.

4.2.3.6 Press the "Alarm Reset" button and verify the "Solution High" alarm extinguishes.

4.2.3.7 Turn on the heating system by pressing the "Heat On" button on the MMI.

4.2.3.8 Verify that the orange "Heat On" indicator is lit, and CO\# is energized.

4.2.3.9 Induce a solution level low alarm by pumping the vessel until the liquid level is below the setpoint on LSL\#.

4.2.3.10 Verify solution low alarm the is visible on the MMI. Ensure that the orange "Heat On" indicator is extinguished, and the light blue "Heat Off: indicator is lit and $\mathrm{CO} \#$ is de-energized. 
4.2.3.11 Press the "Alarm Reset" button and verify the "Solution Low" alarm extinguishes.

\subsubsection{Process Stop interlock.}

4.2.4.1 Turn on the heating system by pressing the "Heat On" button on the MMI.

4.2.4.2 Verify that the orange "Heat On" indicator is lit, and CO\# is energized.

4.2.4.3 Press the system "Process Stop Switch".

4.2.4.4 Verify the process stop alarm the is visible on the MMI. Ensure that the orange "Heat On" indicator is extinguished, and the light blue "Heat Off: indicator is lit and $\mathrm{CO} \#$ is de-energized.

4.2.4.5 Pull the process stop switch to reset the fault and the system.

4.2.5 Power quality monitor interlocks.

4.2.5.1 Turn on the heating system by pressing the "Heat On" button on the MMI.

4.2.5.2 Verify that the orange "Heat On" indicator is lit, and CO\# is energized.

4.2.5.3 Turn SCR Cabinet CB1 from "On" to "Off" (this simulates a loss of phase).

4.2.5.4 Verify the 480 VAC loss alarm is visible on the MMI. Ensure that the orange "Heat On" indicator is extinguished, and the light blue "Heat Off: indicator is lit and $\mathrm{CO}$ is de-energized.

4.2.5.5 Turn SCR Cabinet CB1 from "Off" to "On" to reset the fault power loss fault.

\subsubsection{Partial Load Failure alarm/indicator.}

4.2.6.1 Turn on the heating system by pressing the "Heat On" button on the MMI.

4.2.6.2 Verify that the orange "Heat On" indicator is lit.

4.2.6.3 Turn SCR Cabinet S\# from the "On" to the "Off" position (this will induce a PLF alarm).

4.2.6.4 Verify the PLF lamp the is flashing on the MMI screen.

4.2.6.5 Turn SCR Cabinet S\# from the "Off" to the "On" position.

4.2.6.6 Press the "Alarm Reset" button and verify the "PLF" indicator extinguishes.

4.2.6.7 Turn off the heating system by pressing the "Heat Off" button on the MMI. 


\subsubsection{Turn off the channel for the vessel under test.}

\subsubsection{PLC Fault interlock}

It is not practical to assert a PLC fault to test the channel interlocks. This would require the a PLC reboot for each fault asserted. Therefore, a logic check is required.

4.2.7.1 Refer to the heater control section in the PLC program (ladder logic program) documentation. Verify that a "Normally Closed" PLC Fault bit is in the interlock rung for the vessel under test.

NOTE:

Warning: $480 \mathrm{VAC}$ is present within the SCR Cabinet and the heating system conduits. Ensure all enclosure covers are in place and that the SCR Cabinet doors are closed. Never work in or on this equipment alone.

\subsection{Live tests}

\subsubsection{Auto to manual test}

4.3.1.1 Activate heater power by turning on Circuit Breaker 561 A1$(480$ VAC for vessel \#).

4.3.1.2 On the MMI, turn on the channel for the vessel under test.

4.3.1.3 Verify that the heating system is off, in "Manual" mode and set to $0 \%$ power.

4.3.1.4 Turn the heating system on by pressing the "Heat On" button on the MMI.

4.3.1.5 Verify that the orange "Heat On" indicator is lit, and CO\# is energized.

4.3.1.6 Place the heating system into "Auto" heat mode by pressing the "Auto" push-button on the MMI.

4.3.1.7 Ensure the "Auto" mode lamp is lit and that the "Manual" mode lamp is extinguished.

4.3.1.8 Enter a temperature setpoint of $65^{\circ} \mathrm{C}$.

4.3.1.9 Observe the power control, ensure the \% power increases (towards $100 \%)$.

4.3.1.10 Simulate an over-temperature alarm by lowering the over-temperature alarm setpoint below the solution temperature. 
4.3.1.11 Verify the over-temperature alarm is visible on the MMI. Ensure that the "Auto" mode indicator is extinguished, and the "Manual" mode indicator is lit.

4.3.1.12 Verify the power is set to $0 \%$.

4.3.1.13 Ensure that the orange "Heat On" indicator is extinguished, and the light blue "Heat Off: indicator is lit and $\mathrm{CO}$ \# is de-energized.

4.3.1.14 Set the over-temperature alarm setpoint to $94^{\circ} \mathrm{C}$.

4.3.1.15 Press the "Alarm Reset" button and verify the over-temperature alarm extinguishes.

\subsubsection{Manual power control test}

4.3.2.1 Turn the heating system on by pressing the "Heat On" button on the MMI.

4.3.2.2 Ensure the Manual heat mode lamp is lit.

4.3.2.3 Set the \% power to $50 \%$ (enter " 50 ").

4.3.2.4 Observe the MMI, ensure that the \% power reads $50 \%$ and that the vessel temperature begins to rise. (This could take 1 hour).

4.3.2.4 Set the \% power to $0 \%$ (enter " 0 ").

4.3.2.5 Observe the MMI, ensure that the \% power reads $0 \%$ and that the vessel temperature stabilizes or drops slightly. (This could take 1 hour).

\subsubsection{Setpoint power control test and bake out.}

4.3.3.1 Enter an over-temperature setpoint of $94^{\circ} \mathrm{C}$.

\subsubsection{Enter a temperature setpoint of $90^{\circ} \mathrm{C}$}

4.3.3.3 Place the heating system into "Auto" heat mode by pressing the "Auto" push-button on the MMI.

4.3.3.4 Observe the MMI, ensure that the \% power increases to $100 \%$.

\section{Note:}

Step 4.3.3.5 may take as long as 7 hours to achieve the setpoint and another 4 hours to verify that the setpoint has been maintained. This step can be divided into two days.

4.3.3.5 Carefully observe the vessel and the MMI during the heating process, ensure the vessel solution reaches $90^{\circ} \mathrm{C}$ and maintains this level.

4.3.3.6 Secure the heating system by pressing the "Heat Off" push-button.

4.3.3.7 Secure the channel by pressing the cannel off button. 
This concludes the vessel operational check for vessel \# 


\subsection{Certification}

I certify that vessel system number procedure listed above (appendix A). has passed all requirements set by the

Comments:

Name 